\title{
Continuous monitoring and visualization of optimum spinal cord perfusion pressure in patients with acute cord injury
}

Suliang Chen ${ }^{1}$, Peter Smielewski ${ }^{2}$, Marek Czosnyka ${ }^{2}$, Marios C. Papadopoulos ${ }^{1 \dagger}$ and Samira Saadoun $^{1 * \dagger}$

${ }^{1}$ Academic Neurosurgery Unit, St. George's, University of London, London, U.K.

${ }^{2}$ Brain Physics Laboratory, Division of Neurosurgery, Department of Clinical Neurosciences, University of Cambridge, Addenbrooke's Hospital, Cambridge, U.K.

${ }^{*}$ Corresponding author

${ }^{\dagger}$ Co-senior authors

S. Chen, Academic Neurosurgery Unit, St. George's, University of London, London SW17 0RE, U.K. Email. schen@sgul.ac.uk, Tel. +44 20 87254179, Fax. +44 2087254452

Peter Smielewski, Brain Physics Laboratory, Division of Neurosurgery, Department of Clinical Neurosciences, University of Cambridge, Addenbrooke's Hospital, Cambridge, U.K. Email. ps10011@cam.ac.uk, Tel. +44 1223 336946, Fax. +44 1223216926

Marek Czosnyka, Brain Physics Laboratory, Division of Neurosurgery, Department of Clinical Neurosciences, University of Cambridge, Addenbrooke's Hospital, Cambridge, U.K. Email. mc141@medschl.cam.ac.uk, Tel. +44 1223 336946, Fax. +44 1223216926 
S. Saadoun, Academic Neurosurgery Unit, St. George's, University of London, London SW17 0RE, U.K. Email.ssaadoun@ssul.ac.uk, Tel. +44 20 87254179, Fax. +44 2087254452

M. C. Papadopoulos, Academic Neurosurgery Unit, St. George's, University of London, London SW17 0RE, U.K. Email. mpapadop@sgul.ac.uk, Tel. +44 20 87254179, Fax. +44 2087254452

Running Head: Optimum spinal cord perfusion in acute cord injury

Key words: Autoregulation, Blood pressure, Critical care, Spinal cord injuries, Vasopressor agents 


\section{ABBREVIATIONS}

ASIA, American Spinal Injuries Association

$\mathrm{cCPP}_{\mathrm{opt}}$, continuous optimum cerebral perfusion pressure. Using a sliding 4-hour window that is updated every minute, $\mathrm{PRx}$ is plotted against cerebral perfusion pressure. $\mathrm{cCPP}_{\mathrm{opt}}$ is the cerebral perfusion pressure at which $\mathrm{PRx}$ is minimum, i.e. the cerebral perfusion pressure that optimizes brain vascular pressure reactivity. $\mathrm{cCPP}_{\text {opt }}$ applies to individual patients and is updated every minute.

$\mathrm{cSCPP}_{\text {opt }}$, continuous optimum spinal cord perfusion pressure. Using a sliding 4-hour window, the SCPP of an individual patient is divided into $5 \mathrm{mmHg}$ bins between $40-120 \mathrm{mmHg}$ and the mean sPRx for each bin is computed. sPRx is plotted against SCPP and cSCPP ${ }_{\text {opt }}$ is the SCPP at which SPRx is minimum, i.e. the SCPP that optimizes spinal cord vascular pressure reactivity. $\mathrm{cSCPP}_{\text {opt }}$ applies to an individual patient and is updated every minute.

CSF, cerebrospinal fluid

igSCPP $_{\text {opt }}$, individual global optimum spinal cord perfusion pressure. Using the entire SCPP signal of an individual patient, SCPP is divided into $5 \mathrm{mmHg}$ bins between $40-120$ mmHg and the mean sPRx for each bin is computed. sPRx is plotted against SCPP. $\operatorname{igSCPP}_{\text {opt }}$ is the SCPP at which sPRx is minimum, i.e. the SCPP that optimizes spinal cord vascular pressure reactivity. The igSCPP ${ }_{\text {opt }}$ value applies to the entire signal of an individual patient.

ISP, intraspinal pressure. Pressure of the swollen spinal cord at the injury site, as it is compressed against dura.

MAP, mean arterial pressure

MD, microdialysis 
$\mathrm{pSCPP}_{\mathrm{opt}}$, pooled optimum spinal cord perfusion pressure. Using the SCPP signals of several patients, SCPP is divided into $5 \mathrm{mmHg}$ bins between $40-120 \mathrm{mmHg}$ and the mean sPRx for each bin is computed. sPRx is plotted against SCPP. pSCPP $\mathrm{opt}_{\text {is }}$ the SCPP at which sPRx is minimum, i.e. the SCPP that optimizes spinal cord vascular pressure reactivity. The $\mathrm{pSCPP}_{\text {opt }}$ value applies to the entire patient group.

SCPP, spinal cord perfusion pressure. Mean arterial pressure minus intraspinal pressure. sPRx, spinal vascular pressure reactivity index. This is the running correlation coefficient between ISP and MAP. $\mathrm{sPRx} \leq 0$ indicates intact pressure reactivity, whereas $\mathrm{sPRx}>0$ indicates impaired pressure reactivity TSCI, traumatic spinal cord injury 


\section{ABSTRACT}

The optimum spinal cord perfusion pressure (SCPP) after traumatic spinal cord injury (TSCI) is unknown. Here, we describe techniques to compute and display the optimum SCPP in real-time. We recruited adults within 72 hours of severe TSCI (ASIA grades A-C). A pressure probe and a microdialysis catheter were placed on the injured cord. SCPP was computed as mean arterial pressure (MAP) minus intraspinal pressure (ISP), spinal pressure reactivity index (sPRx) as the running ISP/MAP correlation coefficient and continuous optimum SCPP (cSCPP opt $)$ as the SCPP that minimizes sPRx in a moving four-hour window. In 45 patients, we monitored ISP and blood pressure. In 14 patients, we also monitored injury site metabolism. $\mathrm{cSCPP}_{\text {opt }}$ could be computed $45 \%$ of the time. Mean cSCPP ${ }_{\text {opt }}$ varied by up to $60 \mathrm{mmHg}$ between patients. Each patient's $\mathrm{cSCPP}_{\text {opt }}$ varied with time (standard deviation 10-20 mmHg). Color-coded maps showing the $\mathrm{sPRx} / \mathrm{SCPP}$ curve evolution enhanced visualization of $\mathrm{cSCPP}_{\mathrm{opt}}$. Periods when $\mathrm{SCPP} \approx \mathrm{cSCPP}_{\mathrm{opt}}$ were associated with low injury site glucose, high pyruvate and high lactate. Mean SCPP deviation from $\mathrm{cSCPP}_{\text {opt }}$ inversely correlated with neurological outcome at 9-12 months: ASIA grade improved in $30 \%$ patients with $<5 \mathrm{mmHg}$ deviation, $10 \%$ with $5-15 \mathrm{mmHg}$ deviation and no-one with $>15 \mathrm{mmHg}$ deviation. We conclude that real-time computation and visualization of $\mathrm{cSCPP}_{\text {opt }}$ after TSCI are feasible. $\mathrm{cSCPP}_{\text {opt }}$ appears to enhance glucose utilization at the injury site and varies widely between and within patients. Our data suggest that targeting $\mathrm{cSCPP}_{\text {opt }}$ after TSCI might improve neurological outcome. 


\section{INTRODUCTION}

About 180,000 people suffer a traumatic spinal cord injury (TSCI) each year ${ }^{1}$. The consequences are catastrophic; most patients remain dependent or wheelchair-bound. Currently, the early management of TSCI patients in the neurointensive care unit is variable: In the U.K. there are no clear blood pressure targets ${ }^{2}$ whereas the American Association of Neurological Surgeons' guideline of 85 - 95 mmHg mean arterial pressure (MAP) has little supporting evidence $^{3}$. To aid patient management, we developed techniques for monitoring intraspinal pressure (ISP), spinal cord perfusion pressure (SCPP), spinal pressure reactivity (sPRx) ${ }^{4,5}$ and metabolism ${ }^{6}$ from the injury site. These techniques are safe based on a recent review of 42 patients ${ }^{7}$. In general, the optimum spinal cord perfusion pressure $\left(\mathrm{SCPP}_{\mathrm{opt}}\right)$, defined as the perfusion pressure that minimizes $\mathrm{SPRx}^{5}$, is around $90 \mathrm{mmHg}$. In our original analysis, $\mathrm{SCPP}_{\text {opt }}$ was computed by pooling data from 18 patients ${ }^{4,5}$. Our initial concept of a pooled $\mathrm{SCPP}_{\mathrm{opt}}$ requires revision for several reasons: First, there is now evidence that $\mathrm{SCPP}_{\text {opt }}$ varies between patients ${ }^{8}$ and that the injury site metabolic response is individualistic ${ }^{9}$ thus targeting $90 \mathrm{mmHg}$ may not benefit everyone. Second, the $\mathrm{SCPP}_{\text {opt }}$ of each patient may change with time. Third, the $\mathrm{SCPP}_{\text {opt }}$ can only be computed after the monitoring has been completed and is, therefore, not clinically useful. Here, we show how to compute a continuous $\mathrm{SCPP}_{\text {opt }}(\mathrm{cSCPP}$ opt $)$ in real-time and provide evidence that achieving this $\mathrm{CSCPP}_{\text {opt }}$ may be beneficial after TSCI. 


\section{MATERIALS AND METHODS}

Patient recruitment. Approval for the Injured Spinal Cord Pressure Evaluation (ISCoPE) study, including the patient information sheet and consent form, was obtained from the St George's Joint Research Office and the National Research Ethics Service London - St Giles Committee (No. 10/H0807/23). The study is registered with https://clinicaltrials.gov as NCT02721615. Inclusion criteria are: 1. Severe TSCI defined as American Spinal Injuries Association (ASIA) grade A, B or C; 2 . Age $18-70$ years; 3 . Timing between TSCI and surgery $\leq 72$ hours. Exclusion criteria are: 1. Patient unable to consent; 2. Other major injuries or co-morbidities; 3 Penetrating TSCI. Surgery and early management took place at the neurosurgery and neurointensive care units of St. George's Hospital. Recruitment into the study was discussed with all eligible patients and their families on admission and a patient information sheet was given. Each patient signed a consent form.

Probe placement. Following bony realignment and posterior fixation, a pressure probe (Codman Microsensor Transducer ${ }^{\circledR}$, Depuy Synthes, Leeds, UK) and a microdialysis (MD) catheter (CMA microdialysis AB, Sweden) were tunnelled through skin into the wound cavity. Under the operating microscope, the dura was opened one level below the injury. The pressure probe and MD catheter were inserted through the durotomy and placed on the spinal cord surface. We previously showed that the surface MD catheter samples from the injured spinal cord, not the cerebrospinal fluid (CSF) ${ }^{6}$. The dural opening was sutured and supplemented with fibrin glue (Tisseel ${ }^{\circledR}$, Baxter, UK). The ISP probe and MD catheter were secured to the skin with silk sutures. A wound drain was set at gravity drainage for a week. Patients were given 5,000 units 
dalteparin daily starting on the day after the surgery. Dalteparin was omitted 24 hours before removing the probes and wound drain.

Patient assessments. Neurological examinations were done on admission and at two weeks postoperatively, i.e. before discharge to the rehabilitation facility. A CT and MRI of the whole spine were done on admission. Another CT was done within 48 hours of surgery to check screw and probe positions. MRI of the injured spinal cord was done at about two weeks and at 6-12 months after surgery.

Intraspinal pressure and spinal cord perfusion pressure. The pressure probe was connected to a Codman Intracranial Pressure box linked via a ML221 amplifier to a PowerLab running LabChart v.7.3.5 (AD Instruments, Oxford, UK). Blood pressure was recorded from a radial artery catheter, kept at the same level as the ISP probe, connected to the Philips Intellivue MX800 bedside monitoring system (Philips, Guildford, UK) in turn connected to the PowerLab system. The ISP and arterial blood pressure signals were sampled at $1 \mathrm{kHz}$ for up to a week. LabChart was used to compute SCPP, defined as mean arterial pressure (MAP) minus ISP.

Spinal pressure reactivity. The spinal pressure reactivity index SPRx, a measure of spinal cord vascular reactivity, is the running correlation coefficient between ISP and MAP calculated over a five-minute period as described ${ }^{4,5}$. If the spinal cord vasculature reacts normally, $\mathrm{sPRx} \leq 0$. If autoregulation is impaired, $\mathrm{sPRx}>0$. 
Microdialysis. MD monitoring was started postoperatively in the neurointensive care unit. Central nervous system perfusion fluid (CMA Microdialysis AB, Sweden) was perfused at a rate of $0.3 \mu \mathrm{L} / \mathrm{min}$ using the CMA106 infusion pump (CMA Microdialysis AB, Sweden). MD vials were changed hourly, stored at $4{ }^{\circ} \mathrm{C}$, and batched analysed up to 24 hours later using ISCUS Flex (CMA Microdialysis AB, Sweden). The first two samples from each patient were discarded to allow priming of the MD catheter and stabilization of the metabolite concentrations. All samples were analyzed for glucose, lactate, pyruvate, glycerol and glutamate. 100-fold changes in metabolite concentration, compared with the preceding hour, were excluded from analysis. For details see our earlier papers ${ }^{6,10}$.

Optimum spinal cord perfusion pressure. We used the software ICM+ (www.neurosurg.cam.ac.uk/icmplus). SCPP was divided into $5 \mathrm{mmHg}$ bins between $40-120$ $\mathrm{mmHg}$ and the mean sPRx for each bin was computed. To obtain the pooled $\mathrm{SCPP}_{\text {opt }}\left(\mathrm{pSCPP}_{\mathrm{opt}}\right)$ we used the entire signal of each patient. We averaged the sPRx for all patients in each SCPP bin and plotted these values versus $\mathrm{SCPP} . \mathrm{pSCPP}_{\text {opt }}$ is the minimum of this curve. The same method was used to plot sPRx (averaged for all patients) versus ISP. To obtain the individual global spinal cord perfusion pressure (igSCPP ${ }_{\text {opt }}$ ), we used the entire signal of each patient and plotted sPRx versus SCPP curve for each patient (rather than averaging over all patients). The igSCPP ${ }_{\text {opt }}$ is the minimum of each curve. The same method was used to obtain the individual continuous optimum spinal cord perfusion pressure $\left(\mathrm{cSCPP}_{\mathrm{opt}}\right)$, but by using a four-hour window (unless otherwise stated) rather than the entire signal, moving forward each minute. 
Enhanced visualization. sPRx versus SCPP curves were produced each minute, using a sliding four-hour window. The horizontal axis is time and the vertical axis is SCPP. At each time point, sPRx values are color-coded green (intact reactivity), yellow (borderline reactivity) or red (impaired reactivity). Time points, for which no $\mathrm{cSCPP}_{\mathrm{opt}}$ could be determined, are represented by vertical bands filled with monotonic green. A non-causal, exponentially weighted moving average filter was the applied to the image along the time axis. This filter has a smoothing effect in time and fills in some of the gaps with appropriately weighted average of the preceding and following data values. The measured $\mathrm{cSCPP}_{\text {opt }}$ values were smoothed with the same filter and added to the image. Details are given elsewhere ${ }^{11}$. The images shown here were generated in ICM+ with the current implementation of the MATLAB tool ${ }^{12}$.

Statistical analysis. Two-tailed t-test was used to compare metabolite level within $5 \mathrm{mmHg}$ versus more than $5 \mathrm{mmHg}$ from the $\mathrm{cSCPP}_{\mathrm{opt}}$ with significance at $P<0.01^{* *}$ and $0.005^{\#}$. We used the Spearman coefficient to quantify the correlation between neurological outcome versus deviation from $\mathrm{CSCPP}_{\mathrm{opt}}$ or MAP guideline. 


\section{RESULTS}

Demographics. Table 1 summarizes details of the 45 patients. Most are young, with $84 \%<60$ years old. Males outnumber females by 3.5:1. Cervical TSCIs are more common than thoracic at 56 vs. $44 \%$. Most had neurologically complete TSCI on admission; two thirds were ASIA grade A. Overall, $13 \%(6 / 45)$ patients improved by one grade and $16 \%(7 / 45)$ by at least two grades at 9 - 12 months. Of those who were grade A $17 \%$ improved versus $44 \%$ of grade B and $67 \%$ of grade $\mathrm{C}$.

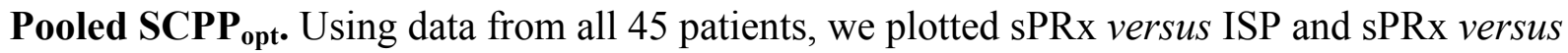
SCPP. Figure 1A shows that as ISP increases, sPRx increases. This suggests that higher ISP correlates with more marked loss of injury site autoregulation. Figure 1B shows a U-shaped relationship between sPRx and SCPP, which suggests that the optimum SCPP is around $80-90$ mmHg. As SCPP falls below $80 \mathrm{mmHg}$ or rises above $90 \mathrm{mmHg}$, injury site autoregulation progressively worsens. Since the optimum SCPP of $80-90 \mathrm{mmHg}$ was computed by pooling data from all patients, we term this pooled $\mathrm{SCPP}_{\mathrm{opt}}\left(\mathrm{pSCPP}_{\mathrm{opt}}\right)$. A major drawback of $\mathrm{pSCPP}$ opt is that it does not provide information about the variability of $\mathrm{SCPP}_{\text {opt }}$ between patients.

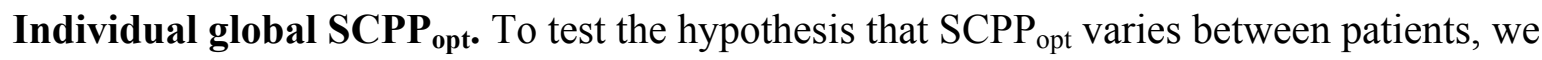
computed $\mathrm{SCPP}_{\text {opt }}$ for individual patients by plotting the sPRx versus $\mathrm{SCPP}$ for each individual patient. We termed this the individual global (igSCPP $\left.{ }_{\text {opt }}\right)$ because it only applies to an individual patient and the entire monitoring period is used. Figure 1C shows SPRx versus SCPP curve for three patients; two had a U-shaped relationship with approximately $20 \mathrm{mmHg}$ difference in their $\operatorname{igSCPP}_{\text {opt, }}$ whereas in one there was no correlation between sPRx and SCPP. igSCPP ${ }_{\text {opt }}$ values 
ranged from $50-60 \mathrm{mmHg}$ in some patients up to $100-110 \mathrm{mmHg}$ in others (Figure 1D). In 13 $\%$ (6/45) patients, igSCPP ${ }_{\text {opt }}$ could not be computed because the relation between sPRx versus $\mathrm{SCPP}$ is not U-shaped. Unlike $\mathrm{pSCPP}{ }_{\mathrm{opt}}$, which is averaged over many patients, $\operatorname{igSCPP}_{\text {opt }}$ provides individual patient information. Because $\operatorname{igSCPP}_{\text {opt }}$ requires the entire ISP and MAP signals, igSCPP ${ }_{\text {opt }}$ does not indicate how a patient's $\mathrm{SCPP}_{\text {opt }}$ changes with time and can only be computed after the monitoring has ended. Thus, igSCPP ${ }_{\text {opt }}$ cannot be used to guide patient management in real time in the neurointensive care unit.

Individual continuous $\mathbf{S C P P}_{\text {opt }}$ To overcome the problems with igSCPP ${ }_{\text {opt, }}$ we computed a running $\mathrm{SCPP}_{\text {opt }}$ for each patient, which we term the individual continuous $\mathrm{SCPP}_{\text {opt }}$, abbreviated as $\mathrm{cSCPP}_{\text {opt }}$, by analogy to the continuous optimum cerebral perfusion pressure $\left(\mathrm{cCPP}_{\text {opt }}\right)$ for brain injury ${ }^{11,13}$. $\mathrm{cSCPP}_{\mathrm{opt}}$ was calculated using a four-hour window, updated every minute. Fig. 2 shows sPRx versus SCPP plots, obtained using four-hour windows. Some plots (plot a) were U-shaped thus allowing $\mathrm{cSCPP}_{\text {opt }}$ to be computed. In other cases, $\mathrm{cSCPP}_{\text {opt }}$ could not be calculated because the injured cord was underperfused (descending curve, plot b) or overperfused (ascending curve, plot c) or there was no correlation between sPRx and SCPP (plot d). We then varied the time window from $2-10$ hours to compute the $\mathrm{cSCPP}_{\text {opt. }}$ For each time window the $\mathrm{SCPP}_{\text {opt }}$ is calculated, the window is moved forward 60 seconds and the $\mathrm{SCPP}_{\text {opt }}$ result is updated. The process continues for the entire SCPP signal. Therefore, when process is finished, there is a $\mathrm{SCPP}_{\text {opt }}$ vector every 60 seconds. Each vector has four components (a, b, c, d) and can be $(1,0,0,0),(0,1,0,0),(0,0,1,0)$ or $(0,0,0,1)$ as follows: a - optimum value found, $\mathrm{b}$ - hypoperfused, c - hyperperfused, $\mathrm{d}$ - no relation between sPRx and SCPP. We then computed the frequencies with which a, b, c, d occur in the entire SCPP signal. The process 
was repeated for each patient. Fig. 2B shows that time windows greater or equal to four hours maximize the chance of obtaining the $\mathrm{cSCPP}_{\text {opt }}$. With a four-hour window, $\mathrm{cSCPP}_{\text {opt }}$ could be computed $45 \%$ of the time. Fig. 3 shows many signals (ISP, MAP, SCPP, sPRx, and cSCPP ${ }_{\text {opt }}$ ) simultaneously displayed for a single patient. $\mathrm{SCPP}-\mathrm{cSCPP}_{\text {opt }}$ is also displayed to allow doctors to see in real-time how their treatment deviates from the optimum.

Histograms of continuous $\mathbf{S C P P}_{\text {opt }}$ We plotted each patient's cSCPP ${ }_{\text {opt }}$ histogram (Fig. 4A). Distributions varied widely; some were unimodal-symmetrical with a predominant $\mathrm{cSCPP} \mathrm{opt}_{\mathrm{ot}}$ peak (patient i) or a wide range of $\mathrm{cSCPP}_{\text {opt }}$ values (patient ii) or bi-modal (patient iii). Left- and right-skewed unimodal distributions were also found (not shown). Fig. 4B shows the standard deviations of these distributions; in most patients, the standard deviation was high at $10-15$ $\mathrm{mmHg}$ and in some as high as $15-20 \mathrm{mmHg}$. The high variability in $\mathrm{cSCPP}_{\text {opt }}$ suggests that a patient's $\mathrm{SCPP}_{\text {opt }}$ is dynamic and, therefore, targeting the same SCPP is inadequate. Fig. 4C shows significant positive correlation between igSCPP $\mathrm{opt}_{\text {and }}$ mean $\mathrm{cSCPP}_{\text {opt. }}$

Neurological outcome. We hypothesized that larger deviation of SCPP from $\mathrm{cSCPP}_{\text {opt }}$ correlates with worse neurological outcome at $9-12$ months. The data show that as the difference between SCPP and the $\mathrm{CSCPP}_{\text {opt }}$ (averaged over each patient's entire monitoring period) decreases, the chance of ASIA grade improvement increases (Fig. 5A) and the chance of having a complete neurological deficit at follow-up (ASIA A) decreases (Fig. 5B). There are only two patients with positive mean deviation of SCPP from $\mathrm{CSCPP}_{\text {opt; }}$ thus, we do not know if hyperperfusion correlates with worse neurological outcome. There was no correlation between the American Association of Neurological Surgeons' guideline of $85-95 \mathrm{mmHg}$ MAP and the chance of 
ASIA grade improvement (Fig. 5C) or the chance of having complete deficit (Fig. 5D) at $9-12$ months.

Enhanced visualization. Displaying $\mathrm{cSCPP}_{\text {opt }}$ as a line (Fig. 3) is clinically helpful, but has drawbacks. First, it fails to show the range of $\mathrm{cSCPP}_{\text {opt }}$ at any one time that are associated with intact autoregulation, i.e. $\mathrm{sPRx} \leq 0$; a cSCPP ${ }_{\text {opt }}$ line simplistically implies that $\mathrm{cSCPP}_{\text {opt }}$ at any one time is a single value rather than a range. Second, the $\mathrm{cSCPP}_{\text {opt }}$ line has gaps whenever the optimum cannot be calculated. We, therefore, used an enhanced visualization technique, recently developed to overcome these issues when monitoring in severe traumatic brain injury ${ }^{11,12}$. Fig. 6 shows two monitoring periods from the same TSCI patient. The top trace shows a wide range (60 $-90 \mathrm{mmHg}$ ) of cSCPP ${ }_{\text {opt. }}$ Initially, the actual SCPP was within this range, but between 00:30 and 01:45 hours the injured cord was hypoperfused. After two days (bottom trace) the range of $\mathrm{cSCPP}_{\text {opt }}$ narrowed substantially. Between 13:00 and 14:00 hours, the cSCPP ${ }_{\text {opt }}$ range was narrow at around $78 \mathrm{mmHg}$, between 14:00 and 16:00 hours it was $65-85 \mathrm{mmHg}$ and, after 18:30, it narrowed again at around $85 \mathrm{mmHg}$. The enhanced visualization technique not only displays the range of $\mathrm{cSCPP}_{\text {opt }}$ values at any one time, but also fills some of the gaps in the signal.

Injury site metabolism. After TSCI, injury site metabolism can be monitored using surface MD ${ }^{6}$. We hypothesized that small deviation of SCPP from $\mathrm{cSCPP}_{\text {opt }}$ correlates with less injury site metabolic derangement. To test this, we quantified the hourly injury site metabolic state in 14 spinal cord injury patients. Figure 7 shows that hourly SCPP close to $\mathrm{CSCPP}_{\text {opt }}$ is associated with low injury site glucose, high lactate and high pyruvate. As SCPP deviates from $\mathrm{CSCPP}_{\text {opt }}$ by 
more than $5 \mathrm{mmHg}$, injury site glucose rises whereas lactate and pyruvate fall. Therefore, $\mathrm{cSCPP}_{\text {opt }}$ does not minimize injury site metabolic derangement, but appears to maximize glucose utilization at the injury site. There was no correlation between deviation from $\mathrm{cSCPP}_{\mathrm{opt}}$ and glutamate, glycerol or lactate-to-pyruvate ratio (not shown). $\mathrm{cSCPP}_{\text {opt }}$ was not associated with a unique metabolic profile (Supplement). 


\section{DISCUSSION}

In this study, we introduced the novel concept of $\mathrm{cSCPP}_{\text {opt }}$, which is a range rather than an individual number. To guide the management of TSCI patients, we showed how $\mathrm{CSCPP}_{\text {opt }}$ could be displayed in real-time using an enhanced visualization method.

Our data show that $\mathrm{cSCPP}_{\text {opt }}$ varies widely between and within patients. Various reasons may explain such wide inter-patient variability: patients with more extensive microvascular damage, pre-existing hypertension or greater leukocyte infiltration at the injury site will likely require higher SCPP. The large intra-patient variability in $\mathrm{CSCPP}_{\text {opt }}$ may be due to the dynamic nature of the pathological processes at the injury site e.g. changes in the numbers of infiltrating leukocytes ${ }^{14}$ and reactive glia ${ }^{15}$ as well as changes in injury site edema ${ }^{16-18}$ and fever ${ }^{19}$. Most $\mathrm{cSCPP}_{\text {opt }}$ distributions are unimodal, but some are bimodal. A bimodal distribution may arise by sudden events that reset the $\mathrm{cSCPP}_{\text {opt }}$, e.g. spinal cord hemorrhage. Further studies are required to clarify the significance of the different $\mathrm{cSCPP}_{\text {opt }}$ distributions. Based on our data, we suggest that targeting the same SCPP continuously in all patients is inadequate.

cSCPP $_{\text {opt }}$ could only be computed $45 \%$ of the time. It would be clinically useful for $\mathrm{cSCPP}_{\text {opt }}$ to be computable more often. One way to achieve this may be by using a Dynamic Adaptive Target of Cerebral Autoregulation algorithm, to combine different sPRx values and time windows in a weighted manner to issue a $\mathrm{CSCPP}_{\text {opt }}$ recommendation. When applied to cerebral perfusion pressure obtained from TBI patients, such an algorithm produced a $\mathrm{CPP}_{\mathrm{opt}}$ recommendation $97 \%$ of the entire monitoring period ${ }^{20,21}$.

Is actively targeting $\mathrm{cSCPP}_{\text {opt }}$ safe? Our audit of 42 patients concluded that insertion of the pressure probe and ISP monitoring for up to a week are safe ${ }^{7}$. However, actively increasing SCPP requires vasopressors, which may produce complications such as cardiac dysrhythmias, 
especially in older patients ${ }^{22,23}$. We previously showed that, after TSCI, the spinal cord swells and is compressed by the dura ${ }^{24}$. Thus, one way to reduce vasopressor requirements is expansion duroplasty, a simple and safe surgical procedure that lowers ISP and sPRx as well as increasing SCPP ${ }^{8}$. Based on our experience thus far, SCPP monitoring is safe and helpful to guide management of TSCI patients ${ }^{25}$.

Is targeting $\mathrm{cSCPP}_{\text {opt }}$ beneficial? Our MD data suggest that $\mathrm{cSCPP}_{\text {opt }}$ maximizes glucose utilization by the injured cells. The Kohonen self-organizing maps ${ }^{9}$ show that each patient's injury site metabolic response is unique. Therefore, each patient's optimal injury site metabolic profile must also be unique, which explains why $\mathrm{cSCPP}_{\text {opt }}$ is not associated with a single metabolic signature (Supplement). How about neurological outcome? We found that larger deviation from $\mathrm{cSCPP}_{\mathrm{opt}}$ (hypoperfusion) is associated with worse neurological outcome at 9 12 months, though the effect of hyperperfusion on neurological outcome could not be determined. Aries et al. ${ }^{13}$ showed that increased deviation from $\mathrm{cCPP}_{\mathrm{opt}}$ is associated with worse neurological outcome after brain injury. These observations suggest that targeting the continuous optimum perfusion pressure may be beneficial after central nervous system injury.

Are there ways of managing spinal cord perfusion without targeting $\mathrm{cSCPP}_{\mathrm{opt}}$ ? One may follow the $85-95 \mathrm{mmHg}$ MAP guideline ${ }^{3}$ or drain CSF with a lumbar catheter ${ }^{26}$. MAPoriented management may be inadequate, evident by the lack of a strong correlation between achieving the guideline and neurological outcome as shown in Fig. 6 and by others ${ }^{23,27,28}$. A major drawback of the MAP guideline is that it does not consider ISP; thus, the same MAP may hypoperfuse the injury site in one patient and hyperperfuse it in another. Also, the MAP guideline does not consider inter- and intra- patient variability in $\mathrm{SCPP}_{\text {opt }}$. Draining lumbar CSF is also likely inadequate because, at the injury site, the cord is not surrounded by CSF, but is 
compressed against dura ${ }^{5,8,24,29,30}$. Thus, CSF drainage is unlikely to reduce injury site ISP. Ultimately, a randomized controlled trial is required to definitively determine whether interventions to achieve $\mathrm{CSCPP}_{\text {opt }}$ improve neurological outcome after TSCI. 


\section{ACKNOWLEDGEMENTS}

Supported by grants awarded to MCP and SS from Wings for Life Spinal Cord Research

Foundation and to MCP from the Neurosciences Research Foundation (Fletcher Fund). We thank the neurosurgeons at St. George's Hospital, King's College Hospital and Hurstwood Park Neurological Centre as well as the spinal orthopaedic surgeons at St. George's Hospital who helped recruit patients. The neuroanaesthetic, neurointensive care and operating theatre staff at St. George's Hospital helped with data collection.

\section{DISCLOSURES}

PS and MC receive royalties for ICM+ from the software licensing fee. 


\section{REFERENCES}

1. Lee, B.B., Cripps, R.A., Fitzharris, M. and Wing, P.C. (2014). The global map for traumatic spinal cord injury epidemiology: update 2011, global incidence rate. Spinal Cord 52, 110-116.

2. Werndle, M.C., Zoumprouli, A., Sedgwick, P. and Papadopoulos, M.C. (2012). Variability in the treatment of acute spinal cord injury in the United Kingdom: results of a national survey. $\mathrm{J}$ Neurotrauma 29, 880-888.

3. Cozzens, J.W., Prall, J.A. and Holly, L. (2013). The 2012 Guidelines for the Management of Acute Cervical Spine and Spinal Cord Injury. Neurosurgery 72 Suppl 2, 2-3.

4. Varsos, G.V., Werndle, M.C., Czosnyka, Z.H., Smielewski, P., Kolias, A.G., Phang, I., Saadoun, S., Bell, B.A., Zoumprouli, A., Papadopoulos, M.C. and Czosnyka, M. (2015). Intraspinal pressure and spinal cord perfusion pressure after spinal cord injury: an observational study. J Neurosurg Spine 23, 763-771.

5. Werndle, M.C., Saadoun, S., Phang, I., Czosnyka, M., Varsos, G.V., Czosnyka, Z.H., Smielewski, P., Jamous, A., Bell, B.A., Zoumprouli, A. and Papadopoulos, M.C. (2014). Monitoring of spinal cord perfusion pressure in acute spinal cord injury: initial findings of the injured spinal cord pressure evaluation study. Crit Care Med 42, 646-655.

6. Phang, I., Zoumprouli, A., Papadopoulos, M.C. and Saadoun, S. (2016). Microdialysis to Optimize Cord Perfusion and Drug Delivery in Spinal Cord Injury. Ann Neurol 80, 522-531. 7. Phang, I., Zoumprouli, A., Saadoun, S. and Papadopoulos, M.C. (2016). Safety profile and probe placement accuracy of intraspinal pressure monitoring for traumatic spinal cord injury: Injured Spinal Cord Pressure Evaluation study. J Neurosurg Spine 25, 398-405.

8. Phang, I., Werndle, M.C., Saadoun, S., Varsos, G., Czosnyka, M., Zoumprouli, A. and Papadopoulos, M.C. (2015). Expansion duroplasty improves intraspinal pressure, spinal cord 
perfusion pressure, and vascular pressure reactivity index in patients with traumatic spinal cord injury: injured spinal cord pressure evaluation study. J Neurotrauma 32, 865-874.

9. Chen, S., Phang, I., Zoumprouli, A., Papadopoulos, M.C. and Saadoun, S. (2016). Metabolic profile of injured human spinal cord determined using surface microdialysis. J Neurochem, doi: 10.1111/jnc.13854. [Epub ahead of print].

10. Chen, S., Phang, I., Zoumprouli, A., Papadopoulos, M.C. and Saadoun, S. (2016). Metabolic profile of injured human spinal cord determined using surface microdialysis. J Neurochem.

11. Aries, M.J., Wesselink, R., Elting, J.W., Donnelly, J., Czosnyka, M., Ercole, A., Maurits, N.M. and Smielewski, P. (2016). Enhanced Visualization of Optimal Cerebral Perfusion Pressure Over Time to Support Clinical Decision Making. Crit Care Med 44, e996-999.

12. Ercole, A., Smielewski, P., Aries, M.J., Wesselink, R., Elting, J.W., Donnelly, J., Czosnyka, M. and Maurits, N.M. (2017). Visualisation of the 'Optimal Cerebral Perfusion' landscape in severe brain trauma patients. Acta Neurochir Suppl, In press.

13. Aries, M.J., Czosnyka, M., Budohoski, K.P., Steiner, L.A., Lavinio, A., Kolias, A.G., Hutchinson, P.J., Brady, K.M., Menon, D.K., Pickard, J.D. and Smielewski, P. (2012). Continuous determination of optimal cerebral perfusion pressure in traumatic brain injury. Crit Care Med 40, 2456-2463.

14. Fleming, J.C., Norenberg, M.D., Ramsay, D.A., Dekaban, G.A., Marcillo, A.E., Saenz, A.D., Pasquale-Styles, M., Dietrich, W.D. and Weaver, L.C. (2006). The cellular inflammatory response in human spinal cords after injury. Brain 129, 3249-3269.

15. Burda, J.E. and Sofroniew, M.V. (2014). Reactive gliosis and the multicellular response to CNS damage and disease. Neuron 81, 229-248. 
16. Burns, A.S., Marino, R.J., Flanders, A.E. and Flett, H. (2012). Clinical diagnosis and prognosis following spinal cord injury. Handb Clin Neurol 109, 47-62.

17. Saadoun, S., Bell, B.A., Verkman, A.S. and Papadopoulos, M.C. (2008). Greatly improved neurological outcome after spinal cord compression injury in AQP4-deficient mice. Brain 131, 1087-1098.

18. Leonard, A.V., Thornton, E. and Vink, R. (2015). The relative contribution of edema and hemorrhage to raised intrathecal pressure after traumatic spinal cord injury. J Neurotrauma 32, $397-402$.

19. McKinley, W., McNamee, S., Meade, M., Kandra, K. and Abdul, N. (2006). Incidence, etiology, and risk factors for fever following acute spinal cord injury. J Spinal Cord Med 29, $501-506$.

20. Depreitere, B., Guiza, F., Van den Berghe, G., Schuhmann, M.U., Maier, G., Piper, I. and Meyfroidt, G. (2016). Can Optimal Cerebral Perfusion Pressure in Patients with Severe Traumatic Brain Injury Be Calculated Based on Minute-by-Minute Data Monitoring? Acta Neurochir Suppl 122, 245-248.

21. Depreitere, B., Guiza, F., Van den Berghe, G., Schuhmann, M.U., Maier, G., Piper, I. and Meyfroidt, G. (2014). Pressure autoregulation monitoring and cerebral perfusion pressure target recommendation in patients with severe traumatic brain injury based on minute-by-minute monitoring data. J Neurosurg 120, 1451-1457.

22. Readdy, W.J., Whetstone, W.D., Ferguson, A.R., Talbott, J.F., Inoue, T., Saigal, R., Bresnahan, J.C., Beattie, M.S., Pan, J.Z., Manley, G.T. and Dhall, S.S. (2015). Complications and outcomes of vasopressor usage in acute traumatic central cord syndrome. J Neurosurg Spine, $1-7$. 
23. Inoue, T., Manley, G.T., Patel, N. and Whetstone, W.D. (2014). Medical and surgical management after spinal cord injury: vasopressor usage, early surgerys, and complications. J Neurotrauma 31, 284-291.

24. Saadoun, S., Werndle, M.C., Lopez de Heredia, L. and Papadopoulos, M.C. (2016). The dura causes spinal cord compression after spinal cord injury. Br J Neurosurg 30, 582-584.

25. Saadoun, S. and Papadopoulos, M.C. (2016). Spinal cord injury: is monitoring from the injury site the future? Crit Care 20, 308.

26. Kwon, B.K., Curt, A., Belanger, L.M., Bernardo, A., Chan, D., Markez, J.A., Gorelik, S., Slobogean, G.P., Umedaly, H., Giffin, M., Nikolakis, M.A., Street, J., Boyd, M.C., Paquette, S., Fisher, C.G. and Dvorak, M.F. (2009). Intrathecal pressure monitoring and cerebrospinal fluid drainage in acute spinal cord injury: a prospective randomized trial. J Neurosurg Spine 10, 181193.

27. Hawryluk, G., Whetstone, W., Saigal, R., Ferguson, A., Talbott, J., Bresnahan, J., Dhall, S., Pan, J., Beattie, M. and Manley, G. (2015). Mean Arterial Blood Pressure Correlates with Neurological Recovery after Human Spinal Cord Injury: Analysis of High Frequency Physiologic Data. J Neurotrauma 32, 1958-1967.

28. Ploumis, A., Yadlapalli, N., Fehlings, M.G., Kwon, B.K. and Vaccaro, A.R. (2010). A systematic review of the evidence supporting a role for vasopressor support in acute SCI. Spinal Cord 48, 356-362.

29. Papadopoulos, M.C. (2015). Intrathecal Pressure After Spinal Cord Injury. Neurosurgery 77, E500. 
30. Phang, I. and Papadopoulos, M.C. (2015). Intraspinal Pressure Monitoring in a Patient with Spinal Cord Injury Reveals Different Intradural Compartments: Injured Spinal Cord Pressure Evaluation (ISCoPE) Study. Neurocrit Care 23, 414-418. 


\section{TABLES}

Table 1. Patients' demographic characteristics.

\begin{tabular}{|c|c|c|}
\hline CHARACTERISTIC & NUMBER & $\%$ \\
\hline \multicolumn{3}{|l|}{ AGE } \\
\hline$\leq 20$ & 3 & 6.7 \\
\hline $21-30$ & 9 & 20.0 \\
\hline $31-40$ & 11 & 24.4 \\
\hline $41-50$ & 8 & 17.8 \\
\hline $51-60$ & 7 & 15.6 \\
\hline $61-70$ & 7 & 15.6 \\
\hline \multicolumn{3}{|l|}{ SEX } \\
\hline Male : female & $35: 10$ & $77.8: 22.2$ \\
\hline \multicolumn{3}{|l|}{ LEVEL OF INJURY } \\
\hline Cervical & 25 & 55.6 \\
\hline Upper thoracic (T1 - T6) & 10 & 22.2 \\
\hline Lower thoracic $(\mathrm{T} 7-\mathrm{T} 10)$ & 3 & 6.7 \\
\hline Conus medullaris (T11 - L2) & 7 & 15.5 \\
\hline \multicolumn{3}{|l|}{ ADMISSION AIS GRADE } \\
\hline A & 30 & 66.7 \\
\hline $\mathrm{B}$ & 9 & 20.0 \\
\hline $\mathrm{C}$ & 6 & 13.3 \\
\hline \multicolumn{3}{|c|}{ AIS GRADE IMPROVEMENT } \\
\hline From A & 2 & 6.7 \\
\hline$>1$ & 3 & 10.0 \\
\hline From B & 2 & 22.2 \\
\hline$>1$ & 2 & 22.2 \\
\hline \multirow[t]{2}{*}{ From C } & 2 & 33.3 \\
\hline & 2 & 33.3 \\
\hline
\end{tabular}




\section{FIGURE LEGENDS}

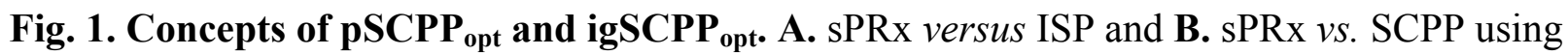
pooled data from 45 patients. Dotted line shows $\mathrm{pSCPP}_{\text {opt. }}$ C. sPRx vs. SCPP for three patients $(a, b, c)$. Dotted line shows igSCPP ${ }_{\text {opt. }}$ D. igSCPP ${ }_{\text {opt }}$ values for 45 patients. Nil means igSCPP opt not computable. Mean \pm standard error.

Fig. 2. Concept of $\mathbf{c S C P P}_{\text {opt }}$ A. Four sets $(\mathrm{a}, \mathrm{b}, \mathrm{c}, \mathrm{d})$ of corresponding ISP, MAP, SCPP and sPRx signals. cSCPP ${ }_{\text {opt }}$ can be obtained in 'a', but not in 'b' (hypoperfused), 'c' (hyperperfused) or 'd' (no relation between sPRx and SCPP). B. \% time versus 'a', 'b', 'c' and 'd' for time windows between $2-10$ hours. Mean \pm standard error.

Fig. 3. Simultaneous display of multiple signals. Simultaneously displayed ISP, MAP, SCPP and sPRx, cSCPP ${ }_{\text {opt }}$ and SCPP $-\mathrm{cSCPP}_{\text {opt }}$ signals from one patient.

Fig. 4. Distribution of $\mathbf{c S C P P}_{\text {opt }}$ values. A. $\mathrm{cSCPP}_{\text {opt }}$ distributions in three patients: $\mathrm{i}-$ unimodal leptokurtic, ii - unimodal pachykurtic, iii - bimodal. B. Standard deviations of the 45

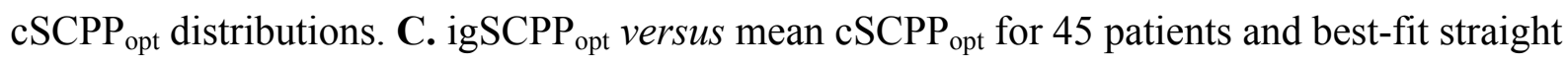
line $\left(R^{2}=0.56\right)$

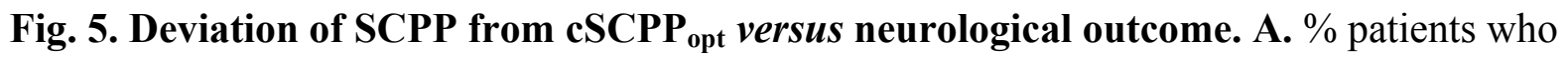
improved by at least one ASIA grade versus mean SCPP $-\mathrm{cSCPP}_{\mathrm{opt}}\left(\mathrm{R}^{2}=0.95\right)$. B. $\%$ patients with complete (ASIA A) neurological deficit at follow-up versus mean SCPP $-\mathrm{cSCPP}_{\mathrm{opt}}\left(\mathrm{R}^{2}=\right.$ 1.00). C. $\%$ patients who improved by at least one ASIA grade $v s$. mean deviation from the $85-$ 
$95 \mathrm{mmHg}$ MAP Guideline $\left(\mathrm{R}^{2}=0.38\right)$. D. \% patients with complete (ASIA A) neurological deficit at follow-up versus mean deviation from MAP Guideline $\left(\mathrm{R}^{2}=0.67\right)$.

Fig. 6. Enhanced visualization of $\mathbf{c S C P P}_{\text {opt }}$ Plots of SCPP versus time for two periods (4 Jan, 6 Jan). sPRx zones: Red (loss of autoregulation), Green (preserved autoregulation) and Yellow (transition from preserved to impaired autoregulation) as per color scale. Line shows actual SCPP.

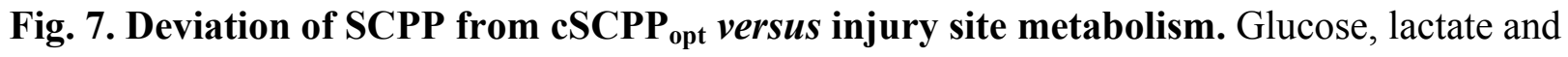
pyruvate concentration versus mean hourly $\mathrm{SCPP}-\mathrm{cSCPP}_{\mathrm{opt}}$. Mean \pm standard error. $P<$ $0.01^{* *},<0.005^{\sharp}$ for metabolite level at ${ }^{-5}-5 \mathrm{mmHg}$ compared with all others together. 
sPRx

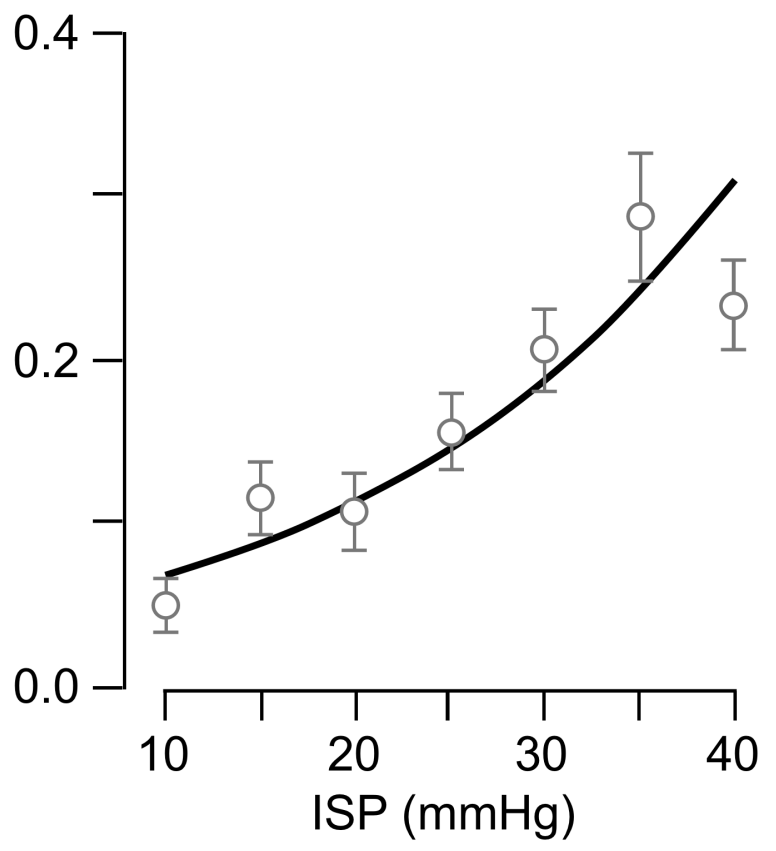

B

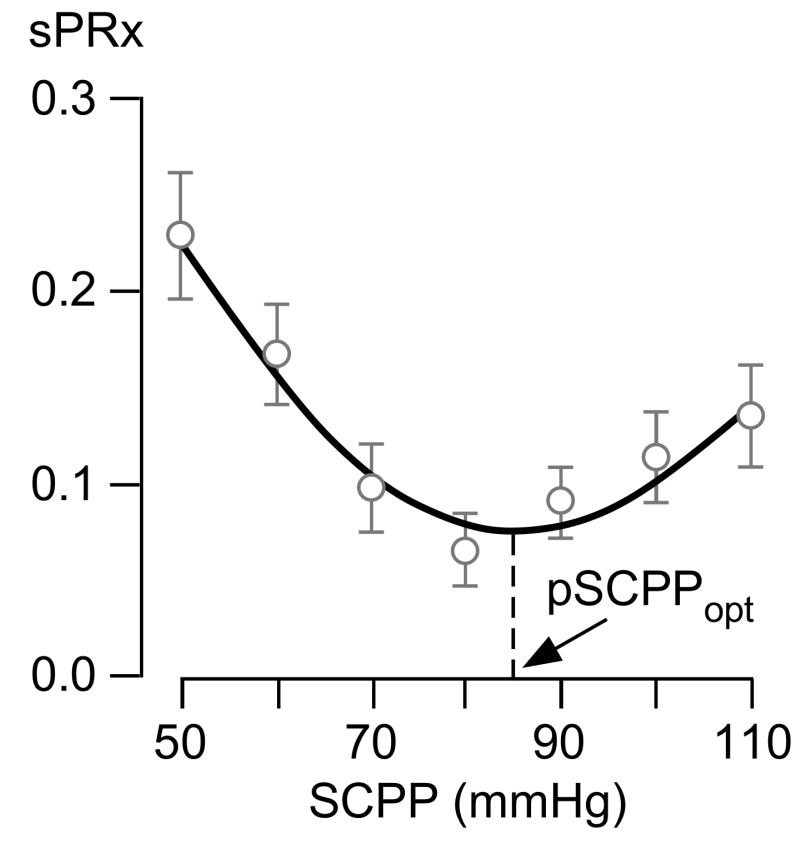

D igSCPP $_{\text {opt }}(\mathrm{mmHg})$

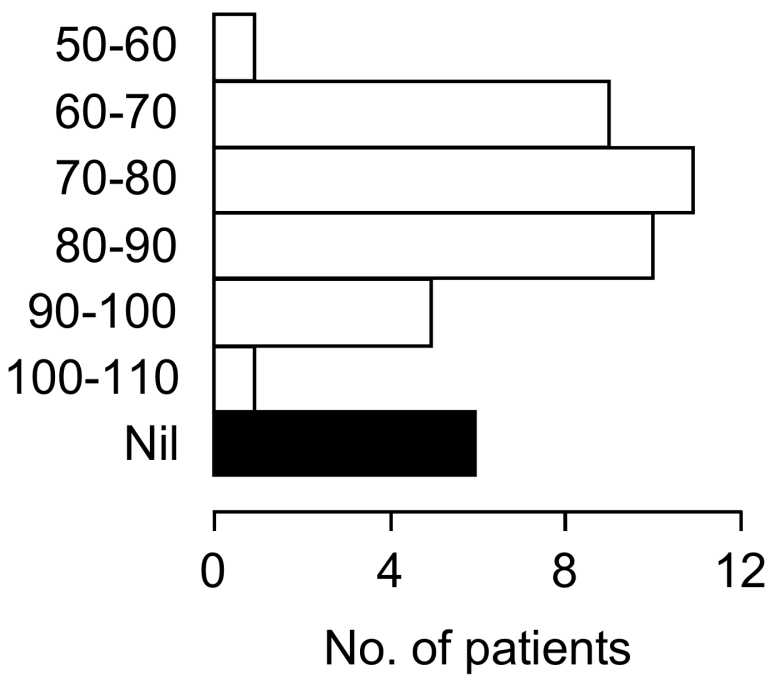



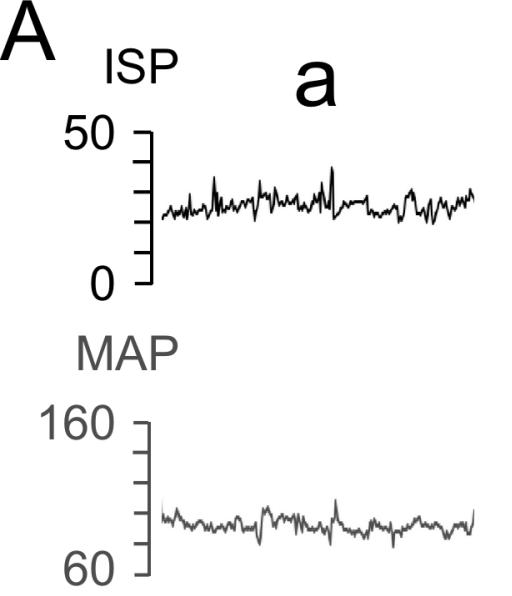

\section{SCPP}

120

100 J

sPRx

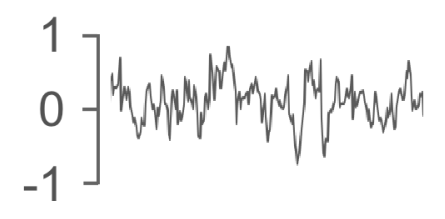

sPRx $1 \mathrm{~h}$

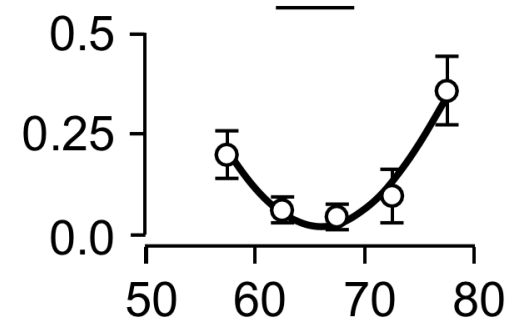

b
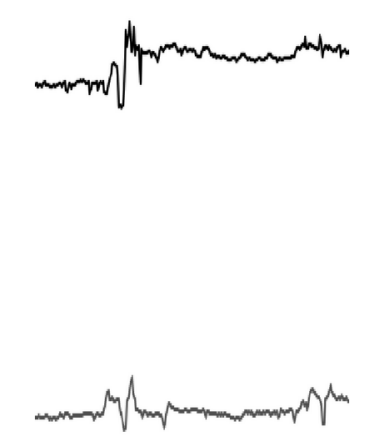

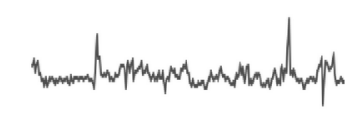
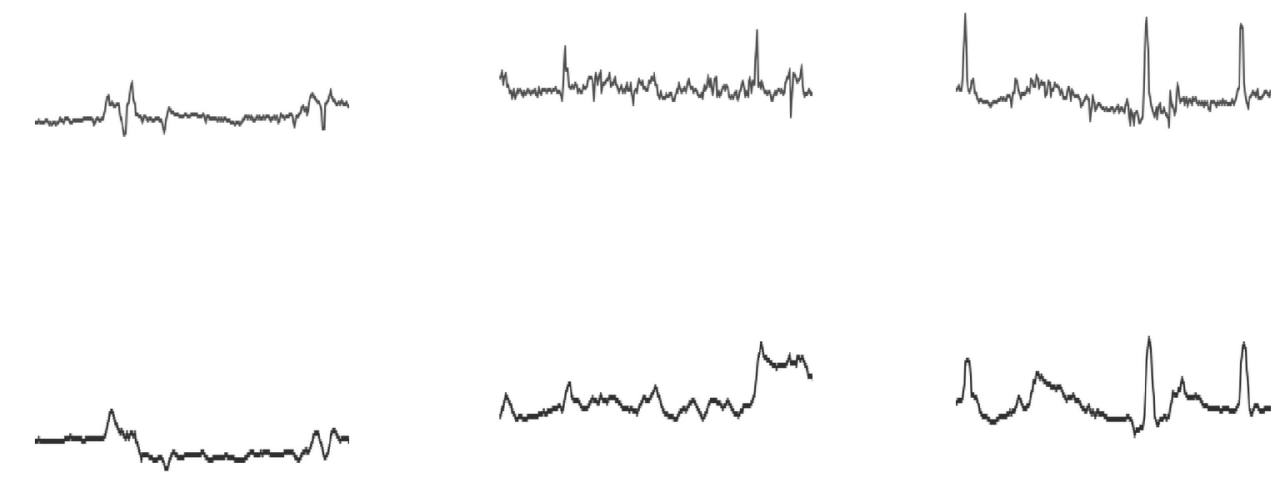

Nom

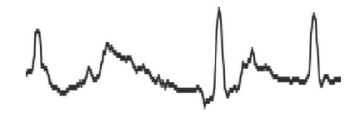

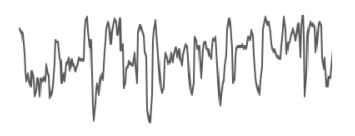

$d$

B

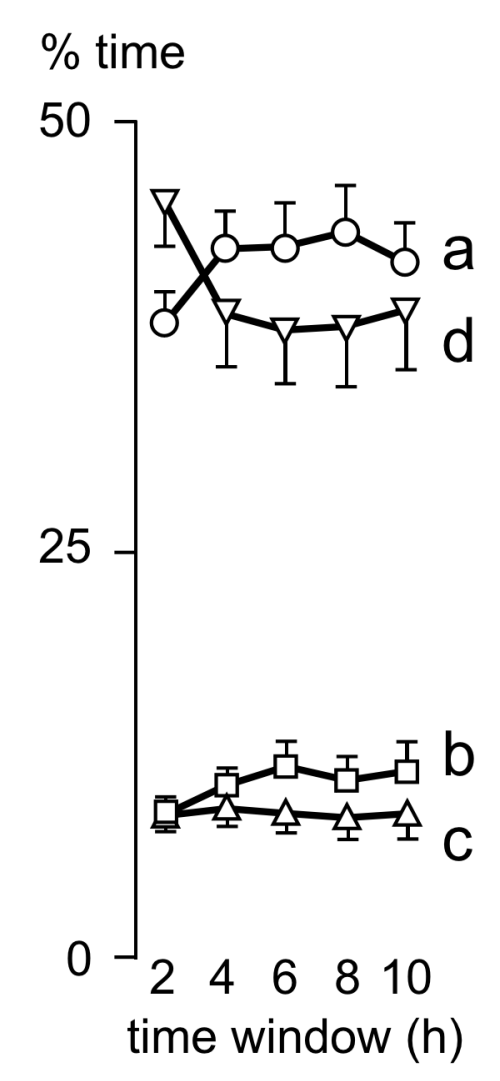

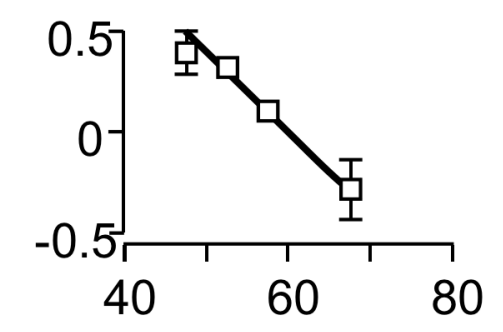

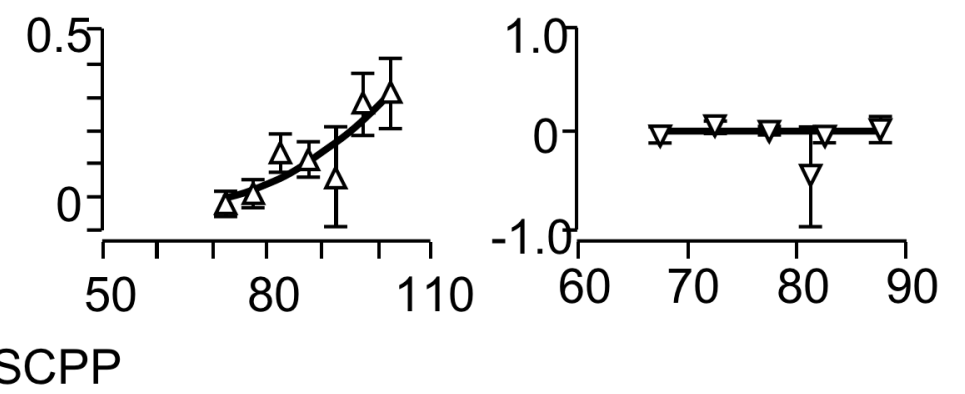




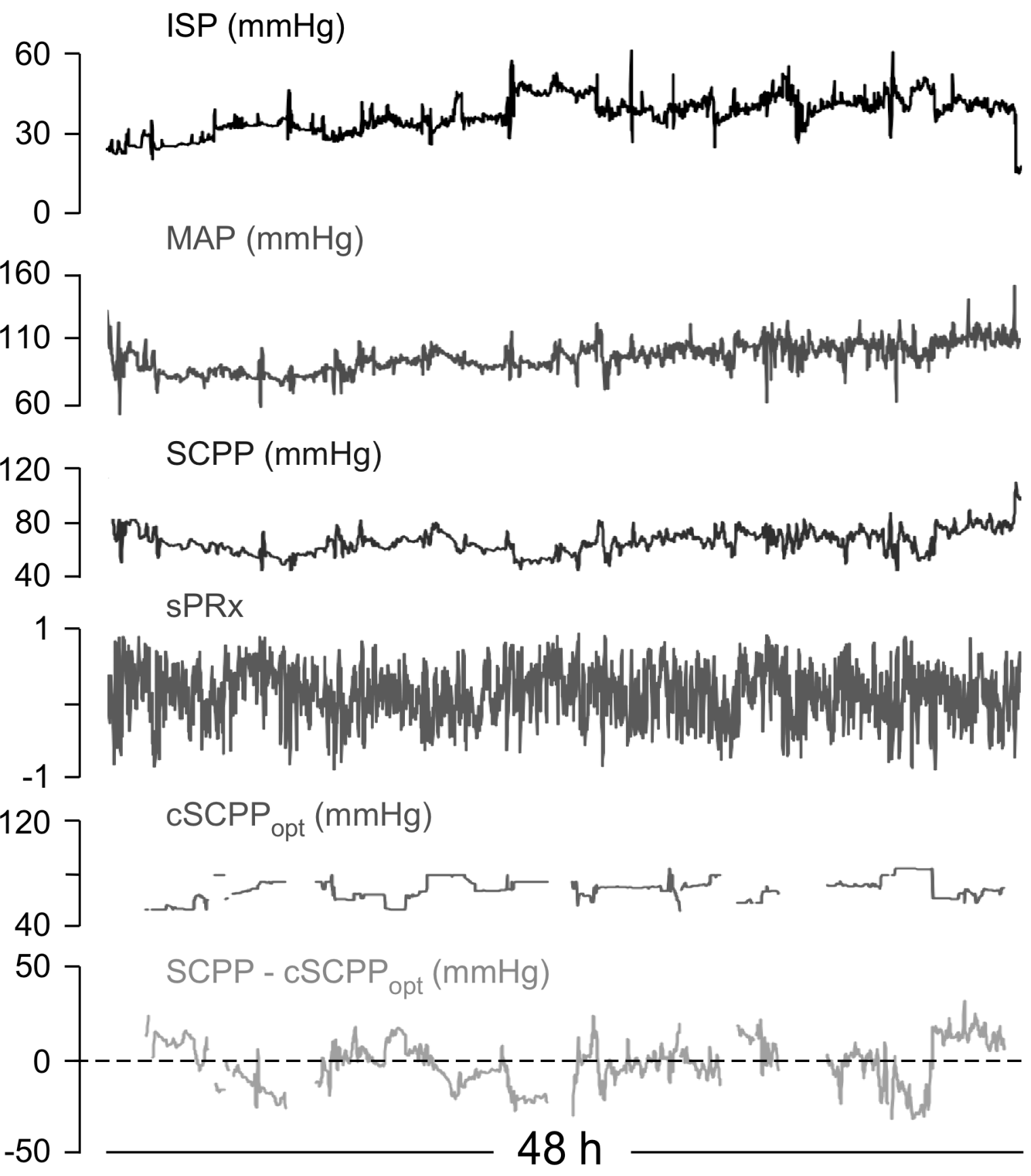


A Density
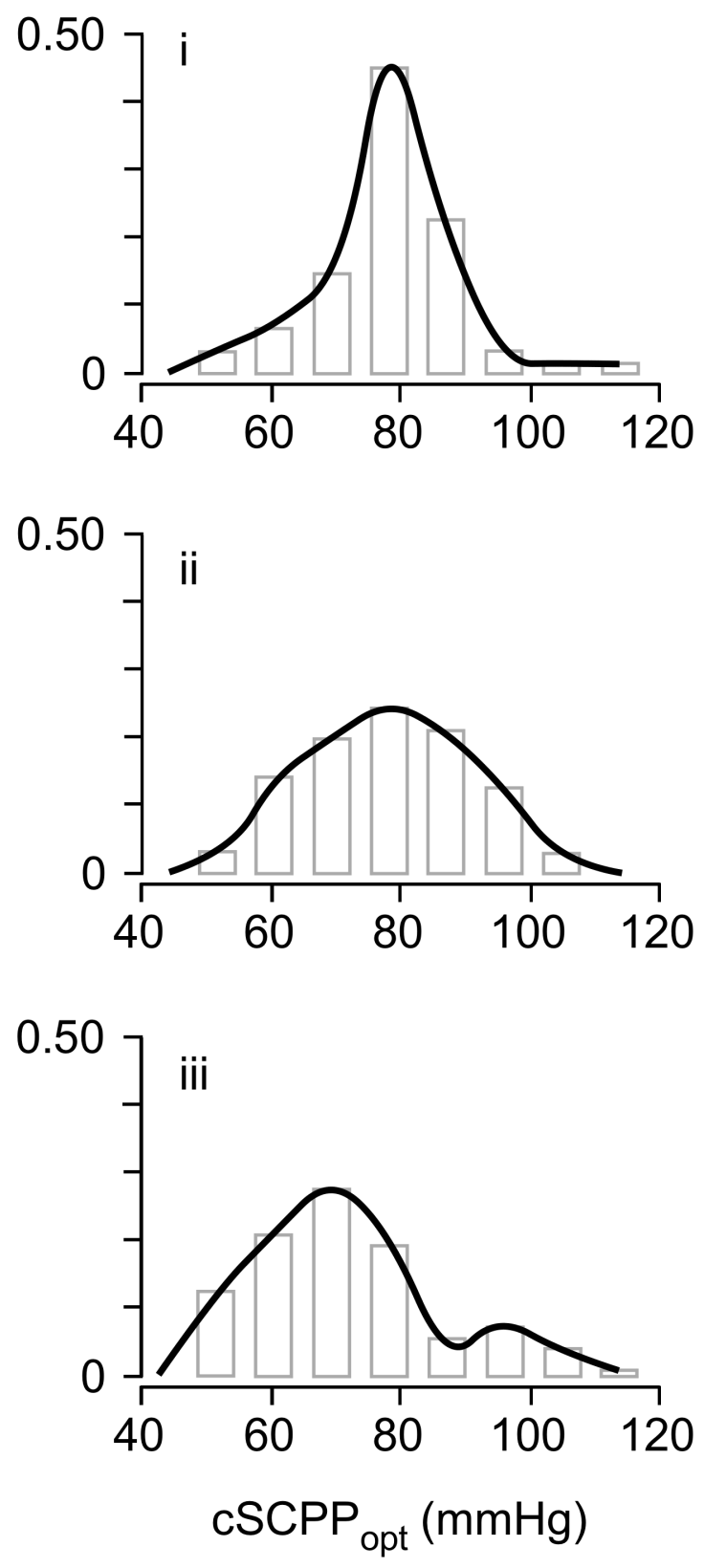

B No. of patients

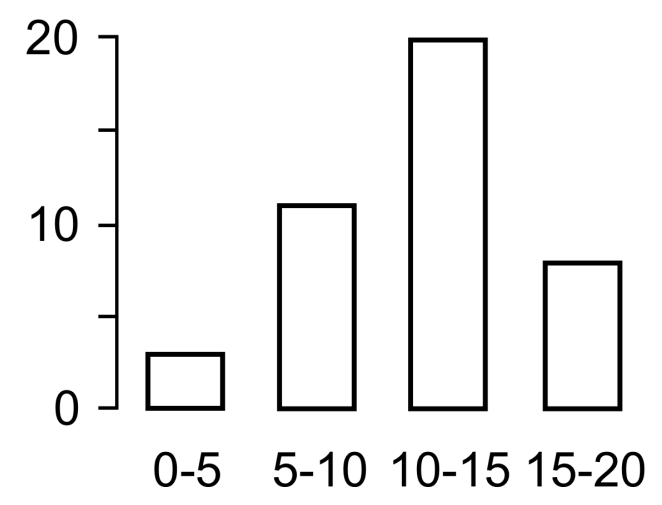

St. dev. of cSCPP

C

igSCPP $_{\text {opt }}(\mathrm{mmHg})$

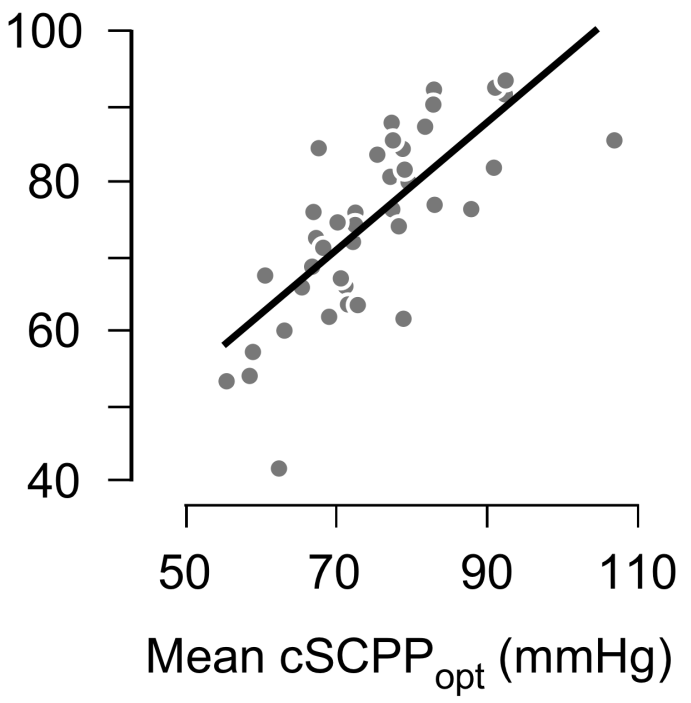


$\%$ patients who improved

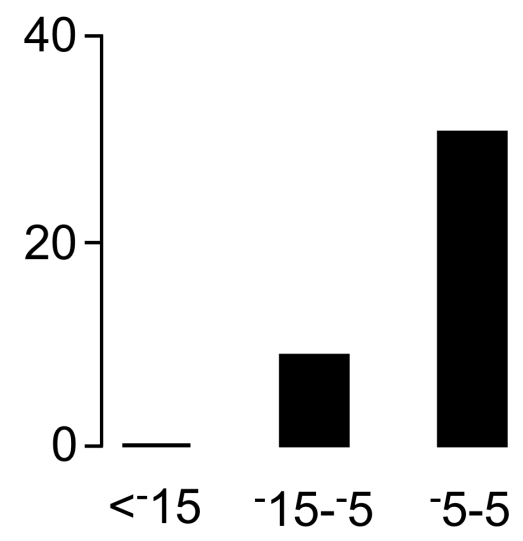

Deviation from cSCPP ${ }_{\text {opt }}(\mathrm{mmHg})$

$\%$ patients who improved

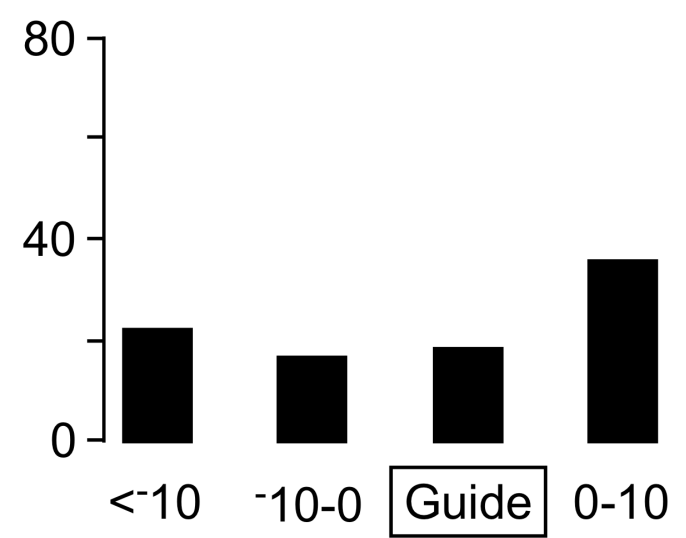

Deviation from MAP guide $(\mathrm{mmHg})$
$\%$ AIS grade A patients at follow-up 100

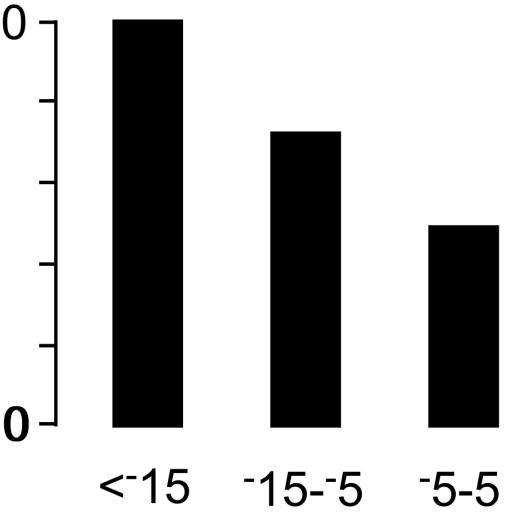

Deviation from cSCPP ${ }_{\text {opt }}(\mathrm{mmHg})$

D \% AIS grade A patients at follow-up

100

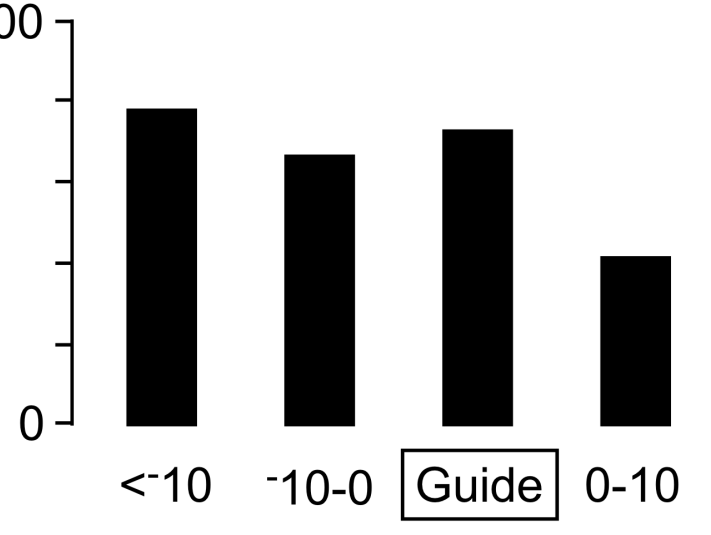

Deviation from MAP guide $(\mathrm{mmHg})$ 
SCPP $(\mathrm{mmHg})$

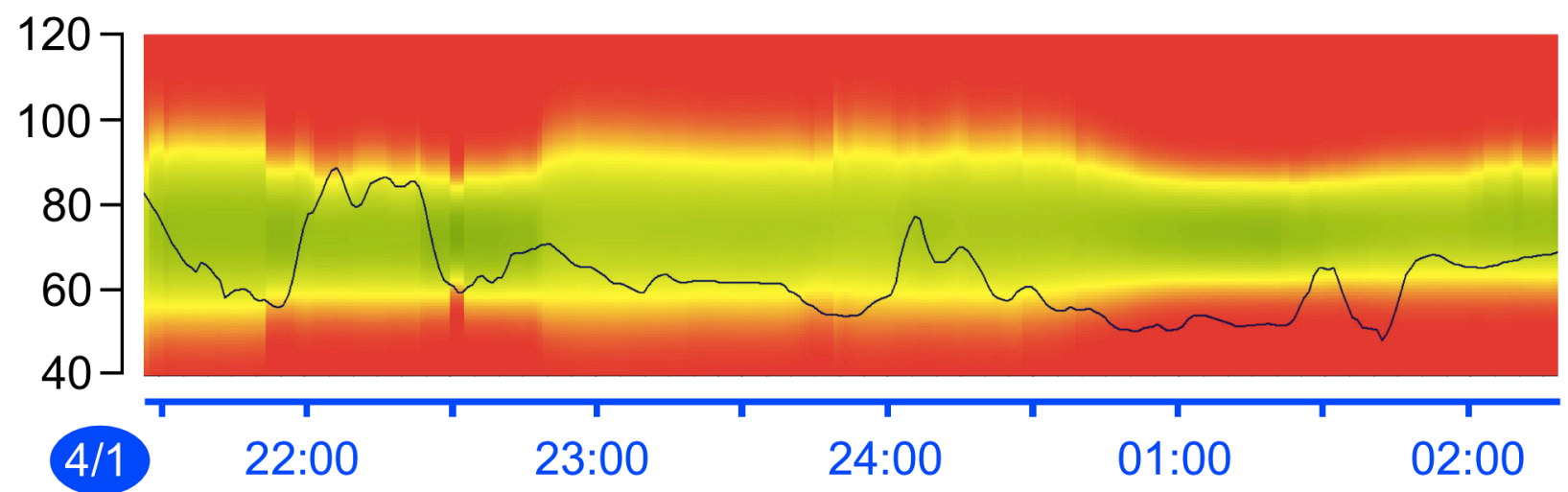

SCPP $(\mathrm{mmHg})$

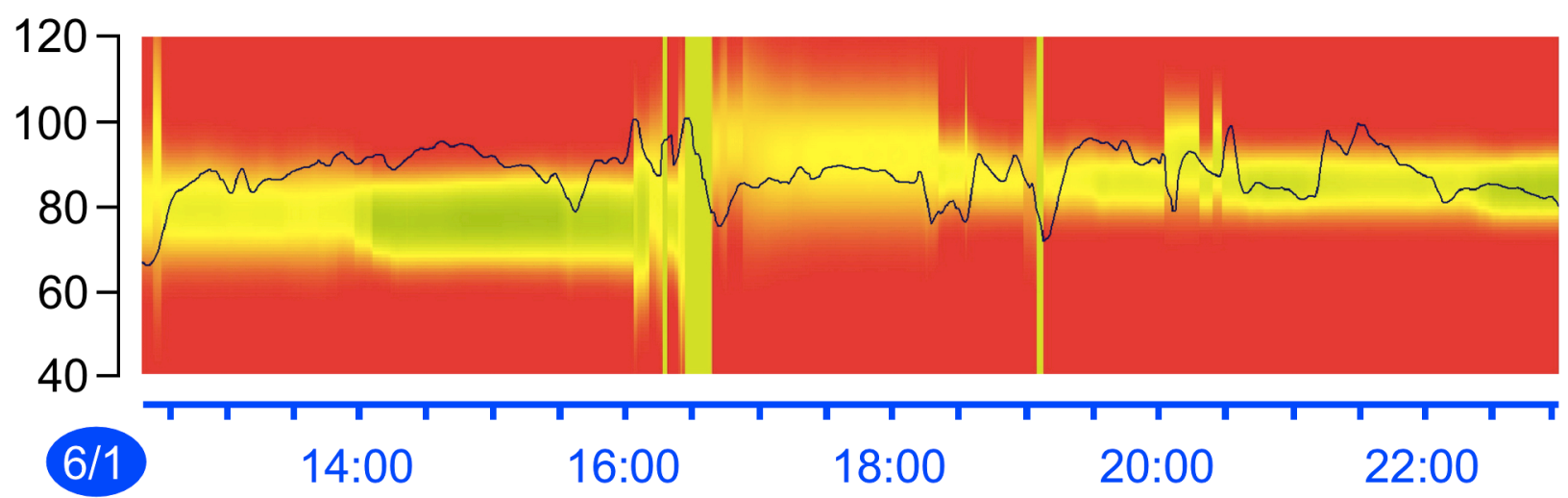

sPRx scale

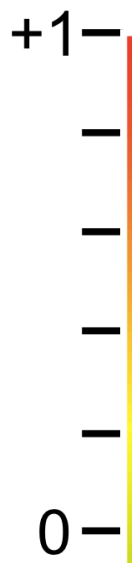

$-$

-

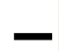

$-$

$-1-$ 
Glucose (mM)

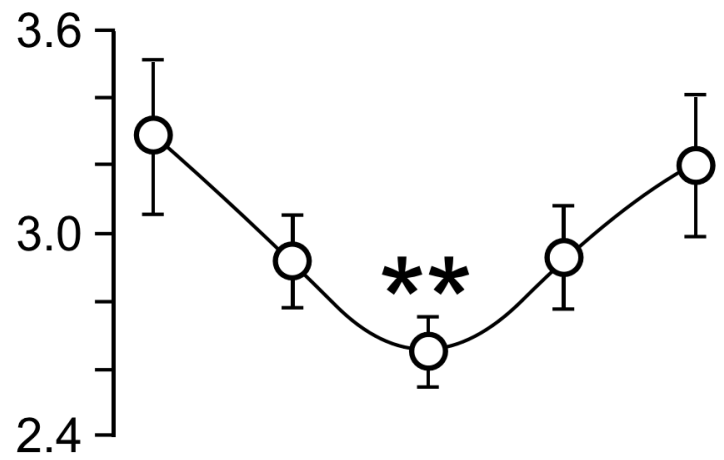

Lactate $(\mathrm{mM})$

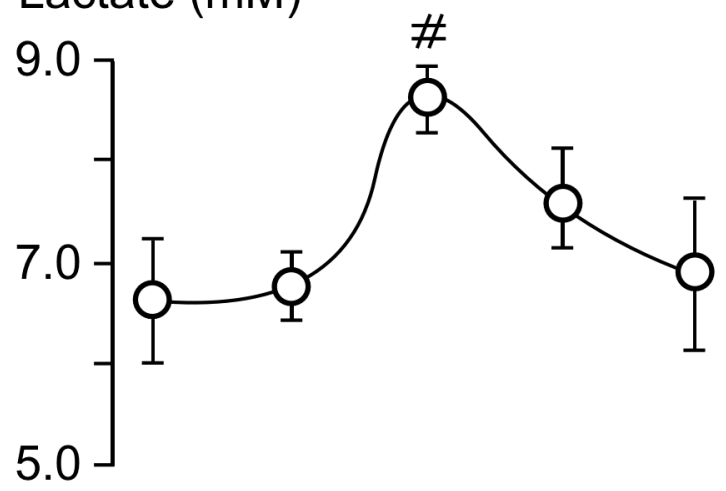

Pyruvate $(\mu \mathrm{M})$

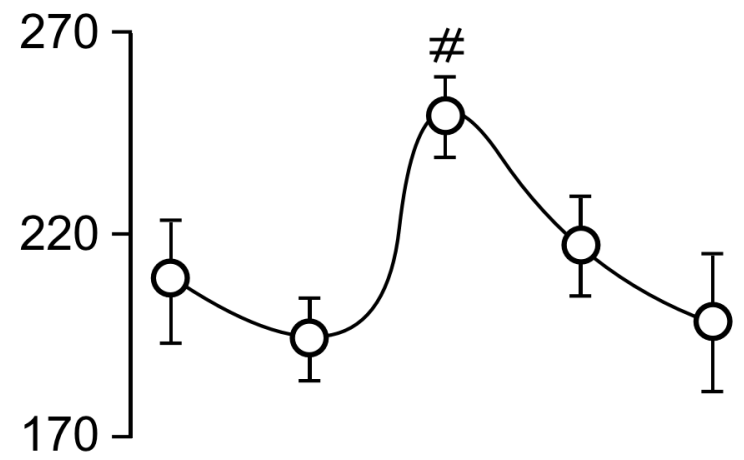

$$
<-15 \quad-15-5 \quad-5-5 \quad 5-15 \quad>15
$$

Deviation from cSCPP opt $(\mathrm{mmHg})$ 


\section{SUPPLEMENTARY DATA}

Kohonen self-organizing maps. We define a vector as a set of five metabolite measurements at a time point. We first removed outliers and interpolated vectors with missing components as we described ${ }^{1}$. After filtering and interpolation, the MD dataset comprised 1,611 five-dimensional vectors. The five metabolites were then normalized to a mean of zero and unit standard deviation. Subsequent analysis was done using the selforganizing map (SOM) toolbox for Matlab v.2.0beta at www.cis.hut.fi/somtoolbox/ ${ }^{2}$. The grid length and width were computed from the ratio between the eigenvalues of the training data. The grid was initialized using random weight vectors as we described ${ }^{1}$. The SOM algorithm uses competitive learning to project the five-dimensional vectors onto a two-dimensional map where similar vectors are cluster close to each other. The algorithm preserves topological relationships between the five-dimensional vectors as they are mapped onto the two-dimensional grid thus facilitating visualization of clinically important, non-linear relationships between the vectors. We colored the Kohonen grid by metabolite level, patient number and mean hourly deviation from the $\mathrm{CSCPP}_{\text {opt. }}$. For details see our earlier paper ${ }^{1}$.

We determined whether $\mathrm{CSCPP}_{\text {opt }}$ is associated with a specific injury site metabolic signature. Supplementary Fig. 1A shows Kohonen metabolite SOMs. The upper part of the SOM indicates high glucose, low lactate, pyruvate, glutamate and glycerol and thus represents near-normal metabolism. The bottom left of the SOM indicates low glucose, high lactate and high pyruvate and thus represents hypermetabolism. The bottom right part of the SOM indicates low glucose, high lactate, medium pyruvate as well as high glutamate and glycerol and thus represents ischemia. Patients occupy different regions of the metabolic map, which suggests that they have individualistic injury site metabolic responses to TSCI (Supplementary Fig. 1B, left). Supplementary figure 1B (right) shows that the yellow hexagons are scattered throughout the map, i.e. having SCPP within $5 \mathrm{mmHg}$ of $\mathrm{CSCPP}_{\text {opt }}$ is not associated with a unique metabolic signature. This finding suggests that the optimum injury site metabolic response differs between patients. 


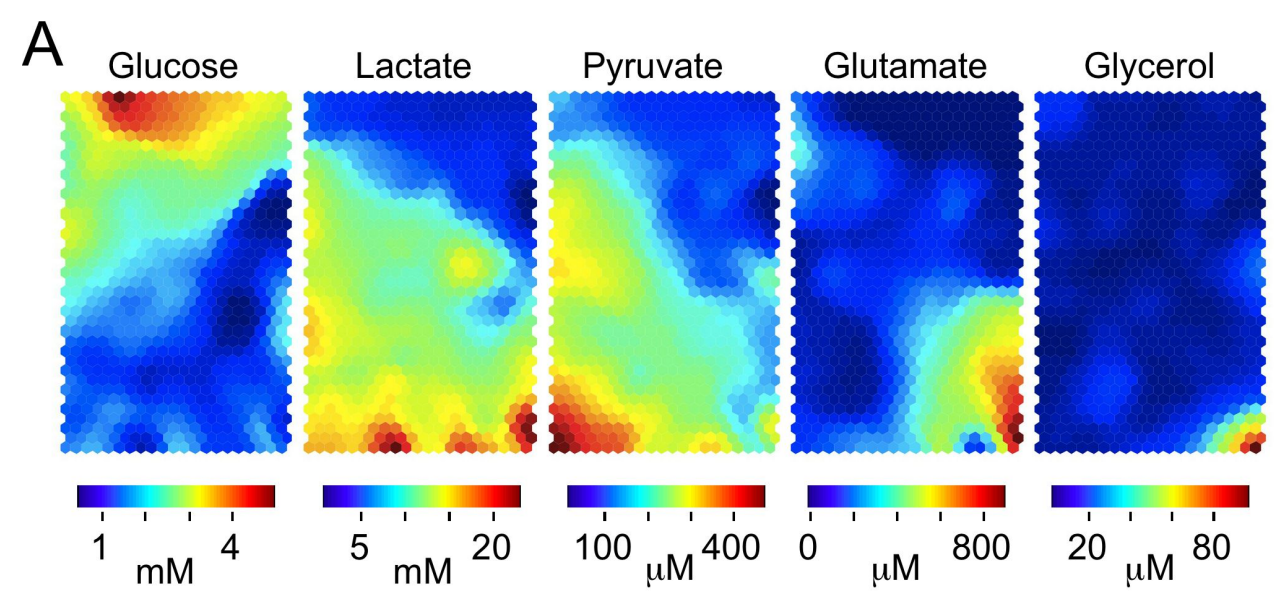

B
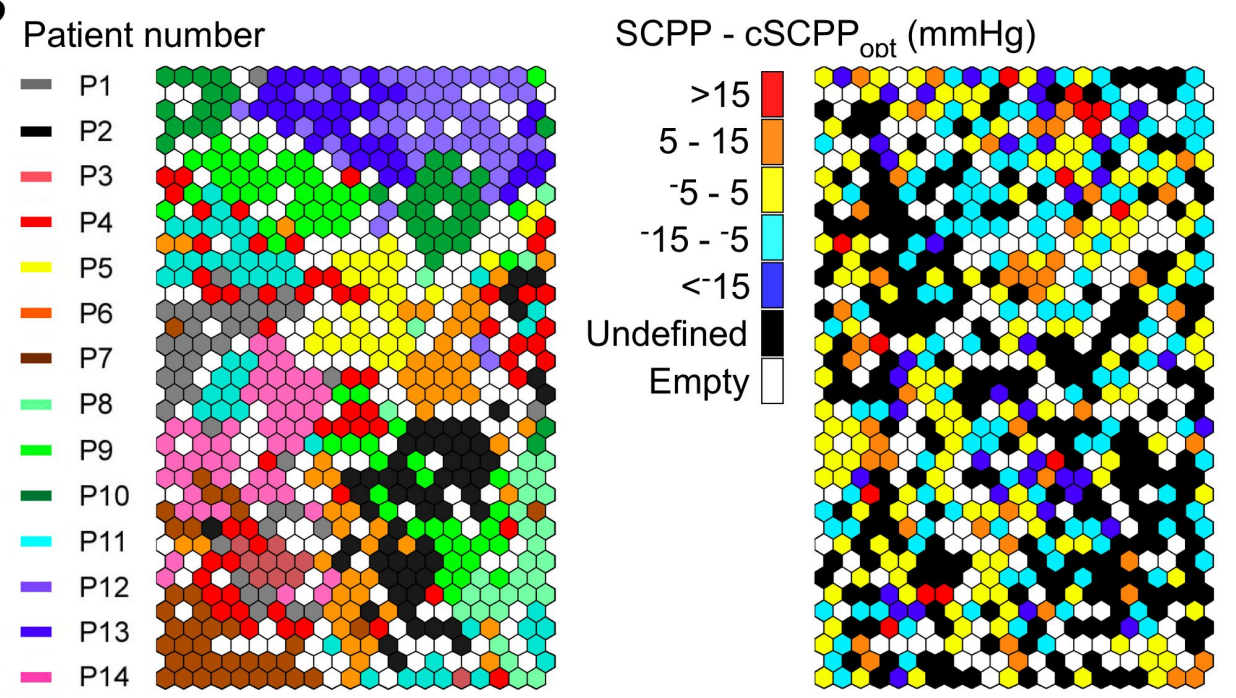

Suppl. Fig. 1. Deviation of SCPP from CSCPP $_{\text {opt }}$ versus injury site metabolism. A. Kohonen SOMs of injury site glucose, lactate, pyruvate, glutamate and glycerol. Heat maps with the average value in each hexagon colour coded. B. (left) Kohonen SOM coloured by patient (P1 - P14). Each hexagon is coloured according to the patient with the most vectors in that hexagon. (right) Kohonen SOM colored according to deviation from $\mathrm{CSCPP}_{\text {opt }}$. Each hexagon is color coded according to its mean SCPP - SCPP opt value.

\section{REFERENCES}

1. Chen, S., Phang, I., Zoumprouli, A., Papadopoulos, M.C. and Saadoun, S. (2016). Metabolic profile of injured human spinal cord determined using surface microdialysis. J Neurochem, doi: 10.1111/jnc.13854. [Epub ahead of print].

2. Kohonen, T. (2013). Essentials of the self-organizing map. Neural Netw 37, 52-65. 